\title{
DOSSIER IN ANATOMY: A TRACKING DEVICE OF LEARNING AND A TOOL FOR ASSESSMENT
}

\author{
Dinesh Kumar. V *, Gunasegaran J.P.
}

Department of Anatomy, Pondicherry Institute of Medical Sciences, Puducherry, India.

\section{ABSTRACT}

Dossier, being one of the available devices for continuous cumulative assessment, is used for inculcating professionalism among medical students mainly during their clerkship. In this article, we have analysed the need for summative assessment in present scenario and how dossier could be effectively crafted in Anatomy. Along with it, we have discussed the rationale behind various parameters used and how it can be used in day to day practice. Further studies need to address the validation of our device and its implications.

KEY WORDS: Cumulative Assessment, Dossier, Medical Education, Professionalism, Anatomy.

Address for Correspondence: Dr. Dinesh Kumar. V, Assistant Professor, Department of Anatomy, Pondicherry Institute of Medical Sciences, Puducherry, India. E-Mail: dinesh.88560@gmail.com

\begin{tabular}{|c|c|c|}
\hline \multicolumn{3}{|c|}{ Access this Article online } \\
\hline \multirow{2}{*}{$\begin{array}{l}\text { Quick Response code } \\
\text { DOI: } 10.16965 / \text { ijar.2017.112 }\end{array}$} & \multicolumn{2}{|c|}{$\begin{array}{l}\text { Web site: International Journal of Anatomy and Research } \\
\qquad \text { ISSN 2321-4287 } \\
\text { www.ijmhr.org/ijar.htm }\end{array}$} \\
\hline & $\begin{array}{l}\text { Received: } 12 \text { Jan } 2017 \\
\text { Peer Review: } 20 \text { Jan } 2017 \\
\text { Revised: None }\end{array}$ & $\begin{array}{l}\text { Accepted: } 16 \text { Mar } 2017 \\
\text { Published (O): } 31 \text { Mar } 2017 \\
\text { Published (P): } 31 \text { Mar } 2017\end{array}$ \\
\hline
\end{tabular}

\section{INTRODUCTION}

All learning programmes has an assessment system at its apex. The level of inclination the students have towards the subject and acumen he or she has gained in the learning programme can be tested only by assessment methodologies. Especially in medical education, where strong baseline knowledge is necessary for a student to pursue further years, assessment systems need to be rigid. The present system, which relies on summative methods in most places and some random formative methods, is archaic. Summative modalities, particularly the present internal assessment method, where cumulative score of monthly / part completion tests is calculated and awarded, might not give the true reflection of the student's knowledge in that particular subject. The summative assessment also lacks in the content validity and there always remains a possibility of examiner bias. The fate of the student in such summativ- eassessment also largely depends on the 'chance' or 'luck' [1].

The formative assessments are conducted in an objective way in most colleges. This can test the learning behaviour of the students regionwise. Since the 1990s, literature has been showing that the reliability of subjective and less structured assessments can be as high as, or sometimes even higher, than that of highly structured objective assessments [2]. Welldesigned formative assessment can focus students on effective learning and divert them away from summative assessment, which focuses attention on grades and reproductive thinking [3].

To suffice the pitfalls in summative assessment and to accommodate the positive aspects of formative assessment, a record maintenance analogous to portfolio in clinical context can be made use of. The use of portfolios for assessment in the health care professions has 
developed as part of a move away from "snap shot" examinations, towards broader methods of assessment [4]. But it is premature to ask the students to maintain the "record" and do a reflective writing on their learning experience. Especially in first year, when the students enter fresh from schools, self-assessment might not be a worthwhile attempt. A modified version of portfolio / dossier which includes the objective skill based assessment and subjective competencies based assessment can help us to provide a complete "track record" of the student.

In traditional assessment methods, when a single teacher assesses a student, that too at a stipulated point of time, the issues of bias and nepotism can creep in. There is a move towards multisource assessment, incorporating self and peer assessment, so that deeper and more authentic learning can occur [5]. Further, owing to summative assessments, many students have the practice of cramming the syllabus few days before or even on the previous night of exam. This may blur out the difference between a student who prepares on a regular basis and a last day crammer, provided "chance" favours the latter.

Though the modern day classrooms have more than 150 students at a point of time, anatomy teaching is bestowed with an advantage of entertaining small groups in dissection and histology labs, aiding more interaction with students. The non-traditional assessment methods can be implemented in a better way exploiting this advantage. With these undercurrent needs in mind, we are suggesting a comprehensive tool for continuous assessment in Anatomy.

\section{METHODOLOGY}

In our cumulative continuous assessment record, we have separate earmarked areas for all regions of gross anatomy. An example of upper limb is given below.

For example in the region of upper limb, student's learning ability can be assessed under cognitive, psychomotor and attitude domains. The teacher in-charge can conduct viva or Objectively Structured Practical Examinations (OSPE) and thereby assess the cognitive domain.
A clinical case scenario or an eponym can be given as an assignment and problem solving skill of the student can be assessed. This can be alternated with other non-traditional assessment methodologies as well. The interest of the student shown towards dissection and the dissecting skill he has acquired can provide a framework of his psychomotor attitude. Attitudinal domain can only be assessed subjectively. The teacher can assess it based on critical analysis, inquisitiveness, assisting peers, ability to work in a team, group ethos and communication skills of that particular student. Thus a student can be assessed in all domains using this tool. This record is then passed on to the subjacent teacher handling the next region and the cycle can be continued. Depending on the pitfalls, a student has in one or multiple parameters, necessary intervention can be planned. Room for summative assessment is also provided in the record which includes the percentile of mark students obtain in theory and practical (spotters) internal assessment at the end of a particular region.

\begin{tabular}{|c|c|c|c|c|}
\hline UPPER LIMB (6wks) & $\begin{array}{c}\text { Viva } \\
\text { (out of 10) }\end{array}$ & $\begin{array}{c}\text { Written test } \\
\text { /Assignment (out of 5) }\end{array}$ & $\begin{array}{c}\text { Practical skill } \\
\text { (out of 5) }\end{array}$ & $\begin{array}{c}\text { Attitude score } \\
\text { (out of 10) }\end{array}$ \\
\hline Pectoral region and Axilla & & & & \\
\hline Shoulder and back & & & & \\
\hline Arm and forearm & & & & \\
\hline Hand and joints & & & & \\
\hline Osteology & & & & \\
\hline Radiology and surface anatomy & & & & \\
\hline Cumulative subtotal score (mean) & & & & \\
\hline Total score (out of 30) with feedback & & & & \\
\hline
\end{tabular}

\section{Histology:}

Majority of the assessment methodologies in anatomy give no room testing the knowledge a student has acquired at the end of histology practical. In our cumulative continuous assessment record, we have included it.

\begin{tabular}{|c|c|c|c|c|}
\hline $\begin{array}{c}\text { Topic } \\
\text { covered }\end{array}$ & $\begin{array}{c}\text { Identification and ability to } \\
\text { use microscope (out of 5) }\end{array}$ & $\begin{array}{c}\text { Discussion } \\
\text { (out of 10) }\end{array}$ & $\begin{array}{c}\text { Ability to draw schematic } \\
\text { diagrams (out of 5) }\end{array}$ & $\begin{array}{c}\text { Assignment / } \\
\text { record (out of 5) }\end{array}$ \\
\hline & & & & \\
\hline
\end{tabular}

\section{DISCUSSION}

Proper assessment of acquired knowledge reflects the student's ability to learn and also gives feedback to teachers who in turn modify the pattern of evaluation as per requirement [6]. Medical schools conduct assessments to certify the competence of future doctors, provide 
motivation and direction for learning and judge the adequacy of training programs [7]. The selection of an assessment instrument is mainly dependant on what the students should have learned. Indeed it has long been established that assessment drives learning [8]. In the present attempt, we have devised a model of continuous assessment device which can help us track a student's progress throughout the learning program.

Developing a 'dossier' in gross anatomy can help us record the performance of the student in an informal way. For any assessment tool, the general parameters like objectivity, reliability and validity has to be met with. The inclusion of multiple parameters makes the tool objectively valid. The examiner /observer bias is mitigated to certain extent here as one student can be assessed by multiple examiners. Reliability means that an assessment consistently achieves the same results with the same or a quite similar cohort of students when administered repeatedly [9]. This can arise in any formative assessment methodologies especially with ambiguous questions. This assessment tool depends on the subjective reliability of the observer. We have framed this keeping in mind the existing situations in practical examinations where an examiner assesses a student in a "snap-shot" and award marks. It can be better replaced with more objective formative assessments depending upon the need. We have framed it keeping in mind the defined objectives a student need to achieve at the end of the learning program, which suffice content validity. The other subsets of validity can be tailored according to the varying backgrounds and syllabi followed by various universities.

To assess the cognitive domain of an individual student, formative assessment like MCQs can be used or a much easier, but subjective viva examination can be used. It is designed to assess the factual knowledge gained by the student over the stipulated period of time. Viva has its own advantage of increasing the level of testing from only recall type of question to highest order of questioning where a student need to synthesize the information to reach the answer. For testing the application knowledge, a clinical case scenario can be given or a patho- logical X ray can be given (eg: Colle's fracture). Psychomotor domain of a student, pertaining to gross anatomy involves demonstration of practical skills i.e, dissection. Comprehensive knowledge regarding structures in a particular region, tidiness and precision in dissection, ability to use appropriate instruments at required time and ability to demonstrate the relationship between different structures in a region are the subsets which need to be tested. Self-exploration forms an important part of dissection [10].

According to Erich Brenner et al., [11] the best method to assess the spatial ability and three dimensional understanding of the students is structured practical examinations and viva voce. In our assessment tool, the spatial ability and three dimensional orientations (psychomotor domain) of subjects can be assessed.

Attitude of the student involves domains which can be inculcated right from the first year of medical education. Gross Anatomy laboratories, based on cadaver dissections, seem to provide the more implicit skills to develop the basic elements of professionalism that are evaluated during clinical rotations [12].

Ability to work as team, helping out peers, treating cadaver as the first patient and group-based discipline can be subjectively assessed. A 'reflection' component or 'internalizing' quotient can be added, if needed. Feedback can be given periodically to make the students learn better. The subcomponent on histology tests the student's ability to identify the slides as spotters and to discuss about. These core elements are necessary in examination point of view with competency to reproduce the diagrams.

Our assessment tool has certain demands in it. First, consistency has to be maintained among assessors and it requires minimum 1:20 ratio of assessor and students. Second, meticulous and unbiased assessment is required as many domains are subjective. Third, stringent vigilance and commitment is required from teachers' side to make the tool, a successful modality. Finally, the students need to be mentored according to the tracking and importance of the record should be insisted to them. If all these demands are met with efficacy, then the tool can be a comprehensively used in anatomy. 


\section{FUTURE DIRECTION AND CONCLUSION}

In future, studies on dossiers and reflective writing should focus on the user-friendliness and feasibility of these in routine academic activities and validate the merits of holistic assessment procedures.

Portfolio use holds the promise to have a learning program that would have a positive academic effect on the learner's knowledge, skills, attitude achieving the highest level of Miller's pyramid [1].This would thereby positively influence the professionalism right from the early days of education in medical school.

\section{Conflicts of Interests: None}

\section{REFERENCES}

[1]. M.K. Joshi, Gupta P And Singh T. Portfolio-based Learning and Assessment. Indian Paediatrics. 2015;52:231-235.

[2]. Vander Vleuten CPM, Norman GR, De Graaff E. Pitfalls in the pursuit of objectivity: Issues of reliability. Med Educ 1991;25:110-18.

[3]. Liu, N. \& Carless, D. Peer feedback: the learning element of peer assessment. Teaching in Higher Education, 2006;11(3):279-290.
[4]. Haldane T. "Portfolios" as a method of assessment in medical education. Gastroenterol Hepatol Bed Bench 2014;7(2):89-93.

[5]. Speyer R, Pilz W, Van Der Krus J et al. Realibility and validity of student peer assessment in medical education: a systematic review. Medical Teacher 2011;33:e 572-e585.

[6]. Agu, A. U., Esom, E. A., Nto, J. N., Anyanwu, G. E., Ezugworie, J. O., Adiri, C. O. and Ozoemena, F. N. Students preference for various types of assessments in anatomy examination International Journal of Development Research, 2014;4(7):1377-1379.

[7]. Epstein RM, Hundert EM. Defining and assessing professional competence. Journal of American Medical Association, 2002 Jan 9;287(2):226-35.

[8]. Biggs J, Tang C (2011) Teaching for quality learning at university. Open University Press

[9]. Sullivan GM. A Primer on the validity of assessment instruments. J Grad Med Educ, 2011, 3(2): 119.

[10]. Lachman N, Pawlina W. Integrating professionalism in early medical education: the theory and application of reflective practice in the anatomy curriculum. Clin Anat. 2006;19(5):456-60.

[11]. Erich Brenner, Andy R.M. Chirculescu, Concepción Reblet, and Claire Smith. Assessment in anatomy. Eur. J. Anat. 2015;19(1):105-124.

[12]. Escobar-Poni B, Poni ES. The role of gross anatomy in promoting professionalism: a neglected opportunity! Clin Anat, 2006;19(5):461-467.

How to cite this article:

Dinesh Kumar. V, Gunasegaran J.P. DOSSIER IN ANATOMY: A TRACKING DEVICE OF LEARNING AND A TOOL FOR ASSESSMENT. Int J Anat Res 2017;5(1):3575-3578. DOI: 10.16965/ijar.2017.112 